EXPECTATIONS, LOSS AVERSION, AND RETIREMENT DECISIONS IN THE CONTEXT OF THE 2009 CRISIS IN EUROPE

NICOLAS SIRVEN, THOMAS BARNAY

$\underline{\text { WWW.tepp.eu }}$

TEPP - Institute for Labor Studies and Public Policies TEPP - Travail, Emploi et Politiques Publiques - FR CNRS 3435 
ISSN 2110-5472 


\title{
Expectations, Loss Aversion, and Retirement Decisions in the Context of the 2009 Crisis in Europe
}

\author{
Nicolas Sirven ${ }^{1}$ and Thomas Barnay ${ }^{2}$ \\ Version accepted for publication - June 2016 \\ International Journal of Manpower
}

\begin{abstract}
We estimate a reduced form model of expectations-based reference-dependent preferences to explain job retention of older workers in Europe in the context of the 2009 economic crisis. Using individual micro-economic longitudinal data from SHARE (The Survey of Health, Ageing, and Retirement in Europe) between 2006 and 2011, we derive a measure of "good, bad or no surprise" from (i) workers' anticipated evolution of their standard of living five years from 2006 (reference point), and from (ii) a comparison of their capacity to make-ends-meet between 2006 and 2011. We find that the probability to remain on the labour market in 2011 is significantly higher for individuals who experienced a lower than expected standard of living. The effect of a "bad surprise" on job retention is larger than the effect of a "good surprise" once netted out from the effects of expectations at baseline, change in consumption utility, and the usual lifecycle determinants on job retention of older workers. We interpret this result as an evidence of loss aversion in the case the reference point is based on individuals' expectations. We also find that loss aversion is more common among men, risk-averse individuals and those with a higher perceived life expectancy.
\end{abstract}

Key words: Job retention, Behavioural economics, Loss aversion, SHARE data

JEL Codes: J26, D03, C23

1. LIRAES (EA 4470) \& Endowed Chair AGEINOMIX, Univ. Paris Descartes, SPC, Paris.

2. Univ. Paris-Est Créteil \& ERUDITE (EA 437), TEPP (FR CNRS 3435) 


\section{Introduction}

The employment rate of older Europeans has been increasing since 2000 as a result of structural reforms of the labour market and pension plans of welfare states, and the 2009 economic crisis did not significantly impact this trend. Retirement decisions in the context of the contemporary "great depression" have been widely studied in the US (Coile and Levine, 2011; Gustman et al., 2010; Goda et al., 2011; Szinovacz et al. 2013) and in Europe (Aranki and Macchiarelli, 2013; García-Pérez et al., 2013; Crawford, 2013). These empirical studies helped clarify the two-sided theoretical mechanisms at play. On the one hand, economic decline and unemployment reduced economic opportunities for job retention and favoured moderate increases in retirement, essentially among lower socio-economic groups. On the other hand, the decrease in the value of assets due to declining stock and housing markets led to modest or non-significant postponement of retirement. By and large, the major economic factors (changes in unemployment, stock market, or housing market) have a contradictory and modest effect on changes in anticipated retirement age and retirement decisions. Goda et al. (2011) suggest that the wealth shocks per se may not have affected shifts in retirement decisions, but rather other factors associated with the crisis and that also correlated with stock market indexes. The authors specifically pinpoint the potential influence of behavioural determinants via economic pessimism. They even assume that the latter could be the "true driver of individuals' perceptions of their retirement security".

Recent studies in behavioural economics shed light on factors other than the standard determinants of retirement provided by the life-cycle framework (see Knoll, 2011 for a review of the literature). Drawing on Prospect Theory (Tversky and Kahneman, 1979), individual choices result from the evaluation of gains and losses relative to a reference point. The models typically incorporate loss aversion: in evaluating outcomes, losses are given more weight than gains. A loss is regarded as an outcome that the decision maker perceives as negative in relation to a reference point. A fundamental issue in reference dependent models is the specification of the reference point. In Koszegi and Rabin's (2006) model of referencedependent preferences considered rational expectations as a reference point. They assume that 
reference point is based on recent outcomes and tied to beliefs about outcomes. A potential, though less studied reference point for older workers is the level of income they expect to earn in the labour market before they retire. "Equating the reference point with expectations [...] is [...] important for understanding financial risk: while an unexpected monetary windfall in the lab may be assessed as a gain, a salary of $\$ 50,000$ to an employee who expected $\$ 60,000$ will not be assessed as a large gain relative to status-quo wealth, but rather as a loss relative to expectations of wealth.” (Koszegi and Rabin, 2006: 1135).

The 2009 economic crisis provides a unique change of context, which could more than usually reveal individual behaviours in the case where their expectations are not met. The crisis can be seen as an exogenous shock to most people, which would lead to changes in the future that individuals did not foresee as they where forming their expectations about their future well-being. Much in line with the target-income literature (Camerer et al. 1997), we expect older workers with a loss relative to expectations of wealth to increase their willingness to work and to postpone retirement. Koszegi and Rabin's (2006) model provides three reasons why workers would have remained at work: (i) higher labour market earnings would help meet the target-income in the following periods, (ii) anticipations of higher earnings foster labour force participation, and (iii) loss aversion associated with inaccurate adverse forecasts, or a "bad surprise", would have led workers to compensate this "loss" by means of higher earnings in the labour market. The main hypothesis we test here is that in case of loss aversion, individuals who experienced a "bad surprise" i.e. a situation where the standard of living was lower than expected, were more likely to remain active on the labour market, ceteris paribus.

The main contribution of this work is to take into account non-standard preferences in individuals' decision to retire or remain on the labour market at older ages in the context of the 2009 economic crisis. Although the determinants of the job retention of older workers in Europe are well documented in the economic literature, the empirical literature devoted to retirement planning and expectations is less studied (Riedel, 2015). One difficulty that needs to overcome is that reference points are not directly observable economic variables. Nonetheless, in the case of expectations as reference points, standard survey questions on individuals' expectations can provide satisfactory proxies. 
Using individual micro-economic longitudinal data from SHARE (The Survey of Health, Ageing, and Retirement in Europe) between 2006 and 2011, we derive a measure of a "bad surprise" from respondents' anticipated evolution of their standard of living in the five years following 2006, and from a comparison of households' capacity to make ends meet in 2006 and 2011. Basically, three situations can arise: (i) "no surprise", when the individuals" anticipations matched the expected situation; (ii) a "good surprise", when they experienced a better situation than they expected; and (iii) a "bad surprise", when individuals anticipated an increase in wellbeing that did not occur. These variables are associated with the usual lifecycle determinants of retirement decision to explain older workers' decision to remain on the labour market in 2011. In the presence of loss aversion, the effect of a "bad surprise" on job retention should be larger than the opposite effect of a "good surprise," once the effects of misapprehension, change in utility consumption, and other individual characteristics are netted out.

The article is organised as follows. Section 2 contains a brief review of the literature of the main determinants of job retention and retirement decisions in terms of the life-cycle model and behavioural economics studies on expectations. In section 3, we present the dataset used and the econometric specifications, with full details on the variables used. The results are presented in section 4 and a discussion is provided in section 5. A number of conclusion are drawn in the last section.

\section{Previous Literature}

2.1. Retirement decisions and job retention of older workers in the life cycle framework

In the life-cycle approach, wealth, health and work conditions are considered as the main drivers of the labour force participation of older workers. Wealth is obviously an important driver of the decision and timing of retirement (Dorn and Sousa-Poza 2005; Bütler et al. 2005). While poorer individuals have less financial capacity to decide between employment and retirement before the legal retirement age, wealthier individuals are more prone to anticipate their departure from the labour market. This being said, wealthier workers have a 
lower utility of leisure and may remain in the labour market longer, especially if they entered the labour market at older ages because of higher education. By and large, individuals who enjoy a higher socio-economic status (SES) tend to work longer than lower SES individuals (Li et al., 2008). Individual preferences play a major role in retirement planning. For instance, Gustman and Steinmeier (2005) show that retirement is often a joint decision between husband and wife.

Health status appears to be one of the most important determinants of the labour market participation of older workers (Barnay, 2015; Lindeboom, 2006). Although the relationship between health status and labour supply appears obvious, the direction of causality is ambiguous (Strauss and Thomas, 1998). Two effects appear to simultaneously play in opposite directions: work conditions can be the source of health deterioration and, at the same time, poor health can be the cause of withdrawal from the labour market. Many empirical studies have shown a "healthy worker effect." Poor health status results in early retirement from the labour market (Alavinia and Burdorf 2008; Jones et al. 2010). Dwyer and Mitchell (1999) show that unhealthy people plan to retire on average 1 to 2 years earlier. GarciaGomez (2011) studies the impact of a health shock on labour-market outcomes in nine European countries on the basis of the ECHP. The results, obtained by applying matching methods, suggest that health shocks have a significant causal effect on the probability of employment: persons suffering from a health shock are much more susceptible to leave their job and transiting through disability.

Job satisfaction and work conditions influence the retirement decision to the same extent as health status (Väänänen et al., 2004; Ferrie et al., 2005). Karasek and Theorell (1990) and Siegrist (1996) developed models revealing the impact of work conditions on health status. Using a longitudinal dataset and cross-country comparisons, Llena-Nozal (2009) and Datta Gupta and Kristensens (2008) showed that a favourable work environment and high job security lead to better health conditions. In addition, job satisfaction is often used as an overall summary of feelings about how workers consider their job. This concept is particularly important as the feelings of work-related satisfaction or dissatisfaction contribute to overall quality of life (Drobnič et al., 2010). Finally, hard working conditions and the degradation of health capital contribute to lower productivity among older workers, increasing their take-up of sick leave and raising the risk of job loss in Europe. 


\subsection{Expectations and retirement decisions}

Aggregate retirement behaviour hides huge differences among individuals. Choi et al. (2014) state that some people make better economic decisions than others and the heterogeneity in choices is linked to differences in preferences, information and beliefs. A number of studies point out the role of expectations on the retirement planning process. Expectations can lead to the establishment of reference points, which may affect the decision of when to retire. For instance, on the basis of a Dutch panel data on retirement behaviour, van Solinge and Henkens (2009) show that workers with a higher perceived life expectancy plan to retire later. The economic theory postulates a certain number of mechanisms through which this indicator modifies individuals' behaviour in the face of retirement: a wealth effect at the end of the life cycle, an uncertainty effect on savings, and an effect related to the risk of longevity. Hurd and McGarry (1995) and Hamermesh (1985) suggest that respondents have a fairly good idea of their probability of living to 75 years old. For Hurd, McFadden and Merrill (1999), the probability of survival is related to both health status and predicted life expectancy. Individuals thus appear to have quite a fairly precise idea of their individual life expectancy and adjust their retirement decision by estimating their life expectancy after retirement (Hurd, Smith and Zissimopoulos, 2004).

Other expectations can also have an impact on the retirement decision such as anticipating future pension reforms. Some studies focus on the adjustment of individuals' retirement expectations following an exogenous chock such as a pension reform. From a German longitudinal study, where respondents reported the age at which they expected to retire, Coppola and Wilke (2014) estimate the impact of the 2007 German pension reform (increase in the SRA from 65 years to 67). Using a difference in differences method, their findings conclude that subjective retirement expectations are more sensitive to policy changes for younger cohorts and high educational attainment groups.

\section{Data and methods}




\subsection{Source and sample}

SHARE is a multidisciplinary and cross-national cohort of individual data on health, socioeconomic status and social and family relationships of more than 100,000 individuals aged 50 or over. Countries that took part in 2004 baseline the project are a balanced representation of the various regions in Europe, ranging from Northern (Denmark, Sweden, and the Netherlands) through Central Europe (Austria, France, Germany, Switzerland, and Belgium), and the Mediterranean (Spain, and Italy). Eastern countries (Poland and the Czech Rep.) joined the project in 2006. Data are collected on the basis of a two-year follow-up schedule and provided prospective panel survey data. The third wave of the project, SHARELIFE, conducted in 2008-09, aimed at extending the panel retrospectively. On this one occasion, respondents were interviewed about their life history. Different fields such as childhood health, education, job career, family life, housing, etc. were surveyed and provided useful information on initial conditions and life course. So far, five waves of SHARE have been made available to researchers.

In this study, we focus on the three waves of SHARE between 2006 (wave 2) and 2011 (wave 4) for three reasons: (i) we are interested in the context of the 2009 economic crisis; (ii) wave 3 provides life-history combined with a unique set of behavioural variables that is not replicated in further waves of SHARE; and (iii) the set of countries expanded to Eastern regions since wave 2 give SHARE a more comprehensive representation of European societies. The initial sample of respondents taking part in the three waves consisted of 17,160 individuals. Since our interest is the change in older workers' labour supply between 2006 and 2011, (i) we keep the 9,452 respondents aged 50 or more at wave 2 and under 70 at wave 4; and (ii) we discard another 5,069 respondents who are not employed in wave 2. The working sample consists of 4,383 employed respondents in 2006 who had either left the workforce, or had remained active on the labour market in 2011 . Notice that $7.5 \%$ of the sample are discarded because of missing data in the set of explanatory variables used. The final sample is composed of 4,054 observations.

\subsection{Variables}


The variable we aim to explain is individuals' change in labour supply between 2006 and 2011. Since all respondents were employed or self-employed in 2006, the explained variable could have just indicated whether the respondent retired in 2011. However, the usual distinction between retired, unemployed, or inactive is not really appropriate in the case of older workers as any kind of exit from the labour force could be analysed as a transitory stage before reaching the statutory retirement age. Claiming public benefits from unemployment and disability statuses for some time are found to be common pathways to retirement in Europe. In order to capture the full dynamics of retirement decisions, the status "retired" was combined with other non-working conditions in a mixed-bag of statuses depicting exit from the labour force. Our goal is not to disentangle the status "retired" from unemployed or inactive statuses. As a consequence, one may say that the variable to be explained is "job retention' between 2006 and 2011. We select all employed or self-employed respondents in 2006 and we estimate the probability of being employed four years later. The dependant variable is dichotomous, taking the value 1 if the respondents self-report in 2011 being currently employed or self-employed, and 0 otherwise.

Our main variable of interest is derived from two subjective measures of expected and experienced changes in living standard between 2006 and 2011. This measure appears in line with the definition of person's reference point from Koszegi and Rabin (2006: 1141) “(...) probabilistic beliefs about the relevant consumption outcome held between the time she first focused on the decision determining the outcome and shortly before consumption occurs". First, respondents are asked in the base year, what the chances (in per cent) were that five years from then their standard of living would be better ("the ability to buy goods and services"), and then, what would be the chance they got worse. If the response is higher than $50 \%$, respondents expected some increase or some decrease in living standard. A third case is considered when respondents with a probability lower than $50 \%$ in both cases were classified as expecting a relative status quo. The very rare cases $(1.2 \%$ of the working sample) when respondents gave contradictory responses (i.e. expecting both increase and decrease in living standard) are considered as missing values; other values are coded (-1) for expected decrease (0) expected status quo or (1) for expected increase. Second, the change in living standard respondents experienced is a simple three-category measure of $(-1)$ decline, $(0)$ status quo, or (1) improvement in income adequacy derived from a self-assessed question that was asked in the base year (2006) and repeated at the following wave (2011): "Thinking of your 
household's total monthly income, would you say that your household is able to make ends meet (1) with great difficulty, (2) with some difficulty, (3) Fairly easily, or (4) Easily." Third, the cross-product of the categorical variables of expectations and experience allow us to define three additional situations: whether the respondents experienced a "bad surprise" (the standard of living of 2011 was lower than expected), a "good surprise" (the standard of living of 2011 was higher than expected), and "no surprise" (the standard of living of 2011 was more or less expected). Fourth, since our variables of interest were based on changes in living standards between waves, we wished to control for other contemporaneous changes in other domains, like health and social. We derive a dichotomous measure of health shock taking the value 1 if the respondent declared the onset of a chronic disease in the period, and 0 otherwise; and a dichotomous measure of change in the marital status - whether the situation vis-à-vis the relationship changed between the two waves.

The usual determinants of labour supply in a life-cycle model included individuals' (i) demographic, social and household characteristics, (ii) health, (iii) wealth, and (iv) work characteristics in the base year.

- We first selected personal characteristics like age (continuous), gender, education (in three levels: lower than high school, high school or college, and university degree), and whether the respondent is a migrant (not born in the country of residence). As family constraints may prove important determinants of labour supply, we retained a set of variables in the base year which depicted whether (i) the spouse is active or inactive, (ii) the respondent is a caregiver (help given outside the household), and (iii) respondents' children aged 18 to 24 in the household are in education, unemployed, or at home. They respectively account for joint husband and wife retirement decisions, informal activities of taking care of an elderly person, and the financial burden of having dependent children in the household, that may reduce the incentive to retain a job.

- We also retain a measure of poor self-rated health, which is a variable dichotomising the US version of self-perceived health into two categories: (0) excellent and very good and (1) less than very good. Since items from the self-rated health scale may represent different things for different people, it is possible to anchor the rating on a set of health measures that better depicts the multidimensional aspect of health (Bound, 1991). A logit model is used to predict poor self-rated health in the base year 
based on individuals' response to the following variables: body-mass index, number of chronic diseases, limitations in activities people usually do, frailty, and depression. A logit model is used to predict poor self-rated health in the base year based on individuals' response to the following variables: body-mass index, number of chronic diseases, limitations in activities people usually do, frailty, and depression. The predicted outcome is simply the individual probability to report less than good health in the base year. We also control for respondents' cognitive capacities in the base year. Measures of education level and cerebral performance are indeed potential confounders of behavioural responses since errors and biases in decision-making are wired into the brain architecture (Kahneman \& Tversky, 1979). More precisely, recent developments in the literature suggest that numerical ability (a proxy for financial literacy), cognition and education level independently predict retirement planning (Altman, 2012; Gerardi, Goette \& Meier, 2013). SHARE developed an objective measure of cognitive functions that comprised both cognitive abilities (memory and verbal fluency performance tests) and numeracy (numerical reasoning performance tests). The combined measure, called 'cognitive performance' is a continuous variable taking its theoretical value between 0 and 1 .

- Wealth is measured as the net amount of households' financial assets in purchasing power parity (PPP). Specifically, the net assets are obtained as the sum of amounts from bank accounts; bond, stock and mutual funds; and savings for long-term investments; minus the amount of financial liabilities. Elements of respondents' work include a categorical variable indicating whether she declared being employee, a civil servant or a self-employed. We also retain a self-reported measure of job satisfaction taking the value 1 if the respondent (strongly) agreed with the following proposition: “all things considered I am satisfied with my job," and 0 if she (strongly) disagreed.

Additional covariates include some retrospective data. Two variables are collected from the wave 3 (SHARELIFE) in order to control for events in the life history of respondents prior to wave 1: whether she experienced (i) periods of financial distress or (ii) health problems over her adult life. The former is a dummy indicating if the respondent encountered any periods of financial hardship throughout her life. The latter is a binary index of health, taking the value 1 if the respondent reports any periods of ill health over the lifecycle ( $>1$ year) or if she reports any physical injury over the lifecycle ( $>1$ year). Two additional behavioural measures are also 
retained: whether the respondent was risk-averse, i.e. whether she reported taking average or no financial risk with regard to savings or investments (1) or taking above than average or substantial risks (0); and whether she expects to live a longer life, coded 1 if she reported a perceived probability to reach a target age higher than $50 \%$, and 0 if she reported $50 \%$ or lower.

\subsection{Econometric Options}

Our aim is to estimate the job retention between 2006 and 2011. Sample selection issues do not seem relevant here since our main interest lies in the effect of a specific set of behavioural determinants on job retention, rather than job employment. Put differently, our analysis focuses on a specific time span (the 2009 economic crisis), so that the determinants of labour market exit before 2006 could be thought as independent from those at stake here. We are confident in using a simple regression framework, as long as the various sources of individual heterogeneity could be addressed, for which SHARE provides a wide set of covariates. Probit models are used in the case of dichotomous outcomes to obtain efficient variance estimation. A reduced-form model is formally written as:

$$
\mathrm{P}\left(\mathrm{y}_{i}^{2011}=1 \mid \mathrm{X}_{i}^{1}, \mathrm{X}_{i}^{2}, \mathrm{X}_{i}^{3}, \mathrm{X}_{i}^{4}, \mathrm{y}_{i}^{2006}=1\right)=\Phi\left(\mathrm{X}_{i}^{1} \beta^{1}+\mathrm{X}_{i}^{2} \beta^{2}+\mathrm{X}_{i}^{3} \beta^{3}+\mathrm{X}_{i}^{4} \beta^{4}\right)
$$

where $\mathrm{y}_{i}$ is the status on the labour market, $\Phi$ the cumulative density function of the normal distribution, $X_{i}$ the explanatory variables, and $\beta$ the parameters to be estimated. Four sets of determinants are considered in turn: $\mathrm{X}^{1}$ represent individual characteristics in the base year inspired from the life cycle framework: they include socio-demographic, health, wealth and work variables; $\mathrm{X}^{2}$ stand for the retrospective life-history variables which complemented the life-cycle model; $\mathrm{X}^{3}$ is the vector of the main behavioural measures of "good and bad surprise." As these variables are derived from a cross-product between two other variables, we also include the expected and experienced changes in standards of living, and potential confounders for change in health and social relationships over the period. Finally, $\mathrm{X}^{4}$ includes additional behavioural measures of risk-aversion and perceived life-expectancy. 
All four sets of variables are included one after the other (stepwise) and a Likelihood ratio (LR) test is performed to evaluate the contribution of the new set of variables to the previous model. In order to gain confidence in the results and to explore the effect of our behavioural measures, we also estimate the model separately for men and women, and for more traditional behavioural measures of risk-aversion and perceived values of life-expectancy.

\section{Results}

\subsection{Descriptive statistics}

Standard variables drawn from the life-cycle framework provide a comprehensive overview of the sample. Table 1 presents some descriptive statistics. First, the population is 56 years old on average, and the share of men $(51.4 \%)$ and women $(48.6 \%)$ is well balanced. The job retention rate is high: $62.3 \%$ of the active population in employment in wave 2 is still at work five years later. Most respondents in the base year are employees (71.2\%), and the rest are either self-employed (15.4\%) or civil servants (13.4\%). They are not particularly satisfied with their job in the base year (only 45.8\%). Second, family constraints are quite important for the so-called 'sandwich generation' since $40.8 \%$ of the sample declare taking care of an elderly person outside the household, and $31.7 \%$ of the respondents have a child in the household who is either in education, unemployed or at home. Third, as expected, respondents at work exhibit a "healthy worker effect" as they report quite a good health status in the base year (only $15.3 \%$ reported poor Self-rated health); and they perform relatively well at the cognitive tests (average score of 0.45 for a maximum at 0.88 ). Nevertheless, a significant share of respondents reports the onset of chronic illnesses over the period $(23.3 \%)$, or reported having had health problems during their adult life (19.8\%). Fourth, respondents' social and economic status (SES) is rather high with regard to educational levels $(37.3 \%$ held a university degree); and only a minority were migrants (6.1\%). Most of the respondents are in a relationship in the base year (82.9\%) and only modest changes in marital status occur over the period $(5.9 \%)$. About half the spouses $(51.8 \%)$ are currently working in the base year. Households hold an average amount of $€ 81.000$ in financial assets (in PPP), but the individual situations seem quite diverse (standard deviation of $+/-€ 181.700$ ) and some 
households exhibit large amounts of debts. About a third of the sample report financial difficulties over their life (35.3\%).

\section{- Tables 1, 2, 3, \& Figure 1 about here -}

Figure 1: Cross-country Effect of Loss Aversion on Labour Supply

Behavioural measures provide complementary information on the sample. On the one hand, statistics describing risk-averse respondents $(68.7 \%)$ or those who forecasted a long life expectancy (58.6\%) are difficult to interpret since a significant number of observations were missing (Table 1). Feedback from the fieldwork suggests that some individuals have difficulties envisaging the context of the question on risk-aversion, as not everyone had the financial capacity to invest or save money. Other people simply refuse to predict their own date of death. On the other hand, our measures based on expectations produce some interesting first results. Tables 1 and 2 indicate that most respondents are able to make consistent forecasts of the evolution of their living standard (89.4\% had "no surprise"). Despite the fact that respondents are essentially pessimistic about their future economic situation (the average expected change in standard of living is negative: -0.044 ), the majority of them benefited from an improvement of their situation (the average experienced change in standard of living is positive: +0.090). These results are consistent with the fact that individuals who experienced a "good surprise" were almost twice as many (6.7\%) as those who experienced a "bad surprise" (3.8\%). However, results in Table 3 (and Figure 1) indicates that the pairwise effect of a "bad surprise" on job retention was significantly higher than the pairwise effect of "no surprise" (respective retention rate of $75.5 \%$ vs. 62.3\%; pvalue $<1 \%$ ), while the effect of a "good surprise" seemed lower and less significant with regard to the same reference (respective retention rate of $56 \%$ vs. $62.2 \%$; p-value $<5 \%$ ). We interpret this initial result as loss aversion, since individuals who did not meet their reference point, remain at work in order to compensate for this loss by obtaining average higher incomes than they would outside the labour market. Those with a "good surprise" tend to leave the workforce sooner, but to a lesser degree, suggesting that individuals attached more to a loss than a gain. Table 3 decomposes the previous result by countries and euro-regions. Unfortunately, the more we go in the detail, the less accurate the estimates became because of 
a lack in statistical power. Nevertheless, the proportions of job retention follow the same pattern across "good and bad surprises."

\subsection{Overall model fit}

Table 4 presents estimates for four sets of variables included one after the other in the models. Estimations for the standard life-cycle model (1) are satisfactory since the estimates have the expected signs and the summary statistics appear adequate: McFadden's pseudo R-squared is greater than $25 \%$ and $77.3 \%$ of the cases were correctly classified. These are similar for the three other specifications. The LR tests for models (2) and (3) suggest that successive inclusion of retrospective life-history data (chi2 $=22.26$, p-val. $<1 \%)$ and expectation-based behavioural variables (chi2 $=50.18$, p-val. $<1 \%$ ) significantly improved the regression fit. However, other behavioural variables such as risk aversion and perceived life expectancy do not seem to be important factors (chi2 $=0.13$, p-val. $=0.937$ ). The addition of these different variables does not significantly modify estimates from previous models, suggesting that our model is quite stable.

Turning to the details, model (1) corroborates standard findings from life-cycle theory. First, older workers are less prone to remain in the working force ( $-8 \mathrm{pp}$. per year old), and women tend to be less present on the labour market at wave 4 ( -5 pp.). Notice that respondents whose spouse is not working in the base year have a higher propensity to leave the labour market (9.6 pp.) which suggests that decisions to withdraw from the labour market decisions are not taken independently. Second, as expected, health status is associated with job retention decisions: in the case of poor self-rated health (-17.8 pp. per 1/100) and cognitive performance (+15.6 pp. per 1/10). Third, individuals with a higher level of SES tended to work longer than individuals with a lower SES. For instance, possessing a university degree (+8.5 pp.), and higher amounts of net financial assets (+1.3 pp. per €10.000) are significant drivers of job retention in wave 4 . Fourth, respondents who reported being satisfied with their job in wave 2 a higher probability to remain in the working force $(+4.9$ pp.). Fifth, there are other individual idiosyncrasies associated with job retention at wave 4 : being a migrant $(+12.7$ pp.), and being self-employed (+17.5 pp.) in the base year. 
Model (2) extends and improves the previous model by adding some retrospective life-history variables. Periods of ill health or physical injury over the lifecycle (that lasted for more than a 1 year) depict the influence of the "long arm" of health conditions on working decisions in later life. Respondents having had previous health issues are less prone to remain in the work force (-9.6 pp.), even after controlling for the current health status in the base year. Periods of financial hardship throughout life appear to play a less important role $(+3.5 \mathrm{pp}$.), maybe because of potential trade-offs with the amount of financial assets the individual accumulated in later stages of her life.

The effects of additional control variables in Model (3) are in line with these aforementioned results. First, inclusion of economic variables corroborates findings from the SES. Individuals who expected a higher gain remained in the labour market (+2.8 pp.) suggesting that financial opportunities are larger in the labour market than outside of the workplace. Individuals, who experience a gain in living standards in 2011, are also more likely to remain in the labour market (+6.4 pp.). Second, changes in health and in social characteristics over the period are added in order to net out the effect other sources of changes between 2006 and 2011 to identify the sole effect of expectation-based behavioural and economic changes. The onset of a chronic disease is negatively associated with job retention ( $-4.1 \mathrm{pp}$.) giving substance to the "health" effect on labour supply. The modification of joint preferences in the couple (change in marital status) seems to play a role in job retention decisions (+6.9 pp.).

\subsection{Main findings}

Models (3) in Table 4 add expectation-based behavioural variables in the extended life-cycle framework. From a behavioural perspective, the expected standard of living in 2011 is the "reference point," the change in living standard currently experienced was the "change in consumption utility," and the potential effect of a "bad surprise" on retirement could be interpreted a measure of "loss aversion" since it depicts a situation where individuals face a loss since they do not reach the reference point. In order for the effect of "bad surprise" to provide proper evidence of loss aversion, it should be bigger than the opposite effect of a 
"good surprise" on labour force participation. Estimates in model (3) for "bad surprise" display the expected sign and is significant (+9.9 pp.; p-val.<5\%), while estimates for "good surprise" have the expected sign were statistically insignificant ( -2.2 , p-val.>10\%). More precisely, results from conditional marginal effects comparison tests suggest rejecting the null hypothesis (equality of the effects of "bad surprise" and "good surprise" in absolute terms) with a p-val. $<10 \%$. This suggests a lack of statistical power. However, the value of the marginal effects and the difference in significance between "bad surprise" and "good surprise" are sufficient to conclude that a "bad surprise" has large effects. We interpret this result as evidence of loss aversion.

The estimates for "good or bad surprise" are not significant in model (4), but this model appears to be miss-specified after other behavioural measures are included. Risk-aversion and perceived life-expectancy are not significant, and the drop in the significance "bad surprise" suggests that this could be (i) due to a loss in statistical power due to a large number of missing values for these variables, and (ii) the result of a potential trade-off with our expectation-based behavioural measures. In order to explore further this issue, model (3) was repeatedly estimated on sub-samples of the population, broken by risk-aversion and perceived life-expectancy; gender is also considered in an exploratory way as men and women exhibit different behaviours with regard to moving or staying on the labour market.

\section{- Table 5 about here -}

Table 5 presents estimates of a decomposition of model (3) by several variables. The results indicate that individuals with a "bad surprise" are likely to remain at work if they are male $(+18.7$ pp.), risk-averse in the base year (+15.1 pp.), and if they expect to live a longer life (+13.2 pp.). The fact that the effect of a "bad surprise" is always significant and large, while the effect of a "good surprise" is never significant and always small, support the "loss aversion" assumption. The interpretation could be that workers have chosen to remain at work in 2011 to compensate for the "loss" they felt with regard to their reference point. The estimates for "bad or good surprise" for females, risk-seekers, and those who expect a shorter life never were significant. Intuitively, one may interpret these results in the following way (i) men are often the main bread earners among the baby-boomer generations, so they may be more sensitive to a loss in economic well-being; (ii) risk-averse individuals could also be 
more sensitive to a loss; (iii) individuals with higher perceived life-expectancy could compensate for the loss more easily since they had more time to spend in the labour market. In all cases, these result support the behavioural assumption that individuals facing loss aversion tend compensate the "loss" (with regard to a reference point) by prolonging work activity before retirement.

\section{Discussion}

\subsection{Limitations}

We acknowledge this work has some limitations that could provide directions for further research. First and foremost, we fail to endogenise the reference point as suggested in Koszegi and Rabin (2006). The criticism is that the reference point is a free parameter to be determined by the researcher (e.g. Pesendorfer 2006). Nonetheless, we tried to consider the expected change in living standard as a predicted outcome of lagged measures of ability to make-ends-meet in wave 1 (2004). The increase in the longitudinal dimension reduced the statistical power of the sample and the estimated models yielded non-significant results.

We also fail to endogenise the effect of the experienced gain or loss on exits from the labour market, leaving us with a potential reverse causality issue. Respondents who remain in the work force tend to earn higher average incomes, while those who earn more, are less prone to exit from the labour market. Tackling this issue proved quite hard since the use of instrumental variables may be complex (i) with the econometric set up to carry out as our behavioural variables were derived from the cross-product of two variables, and (ii) with regard to the choice of the instruments. However, if we discard the issue of the reference point discussed above, the expected gain or loss in living standard was mainly considered as a control variable for a "good and bad surprise."

Although the initial aim was to carry out cross-country comparisons in loss aversion and retirement decisions, the small proportion of "bad surprises" combined with the a relatively small sample size made thus difficult, if not meaningless, to explore cross-country differences. More generally, survey data in behavioural economics are a scarce resource, 
usually not initially designed to carry out this kind of analysis, so that data limitations are a general limitation to overcome. A closer link between research needs and survey data production would be beneficial, as the success of the SHARE project demonstrates.

\subsection{Avenues for further research}

Our results are based on the assumption that respondents' reference points were stable over time, and that the assessment of their economic well-being was consistent over the period. We have no evidence supporting this assumption. In theory, an individual's assessment of her situation could be time-inconsistent. For example, although the standard of living did decrease, adaptive behaviours (Cros, 2008) could have made the respondent under-estimate the loss in economic well-being as she gradually got used to her new living standard. Recent developments in economic theory suggest that preferences may change with circumstances when properties of the agent's alternative choices are modified (Dietrich \& List, 2013). The experimental literature finds that changes in individual preferences may have occurred during the great recession (Fisman, Jakiela \& Kariv, 2015).

This alternative assumption has theoretical and practical implications. From a theoretical perspective, this would have provided a similar result as a shift in the reference point (e.g. Arkes et al., 2008; Schwartz et al., 2008; Masiero and Hensher, 2011) and goes back to the issue on how to endogenise the reference point in empirical studies. From a practical perspective, it suggests that there is a potential over or under-estimation of the "good or bad surprise." For instance, workers would have taken into account the average reduction in labour incomes due to the crisis, so that a change in agents' expectations could have meant that agents modified the reference point to a lower level. As a consequence fewer cases of 'bad surprise' would have occurred than what was accounted for, so the effect of the variable 'bad surprise' on job retention would have been reduced. Despite this potential downward bias, our results still support the main assumption that a 'bad surprise' has a strong and persistent effect on job retention. The use of objective measures such as change in income amounts could reduce the reporting bias, but would leave us uninformed about how the individual rated her on living standard, i.e. whether she feels she reached the reference point or not. Since there is to our knowledge no evidence on this issue, we believe further research could use longitudinal anchoring vignettes from SHARE to explore the issue of time- 
consistency in the assessment of the living standards between individuals and over time, netted out from respondents' differential item functioning (Bonsang and van Soest, 2012; Angelini et al., 2011).

As already mentioned, our expectation-based measures of preferences only identify a small proportion of the population outside the range of rational expectations, since only about $10 \%$ of the sample experienced a "good or bad surprise." Robustness checks based on a broader definition of "good or bad surprise." (e.g. expecting the status quo and experiencing a loss) do not yield significant results, which suggests that the "loss" with regard to the reference point must be somehow substantial. In this case, one may assume that individuals with higher cognitive capacities tend to make more accurate anticipations. From a theoretical perspective, Tversky and Kahneman (1991) assume that reference dependence with loss aversion is a form of non-standard preferences linked to cognitive ability. Behaghel and Blau (2012) showed that US older workers with higher cognitive ability adapted better to a change in statutory retirement age. Nevertheless, in our case, loss aversion remains significant after we control for an objective measure of respondents' cognitive ability. This result gives substance to the alternative assumption of affective forecasts (Wilson and Gilbert, 2003) which suggests that prediction errors could happen when mental simulations are decontextualized, i.e. the contextual factors that are present at the time an individual mentally simulates a future event may not be present at the time the event actually occurs. This could typically be in the case of some exogenous shock just like the 2009 economic crisis.

\section{Conclusion}

We estimate a reduced form model of expectations-based reference-dependent preferences to explain job retention of older workers in Europe in the context of the 2009 economic crisis. We assume that an individual's expectation of her living standard in the near future was her reference point. Individuals who face a "bad surprise" i.e. they experienced a lower than expected level of economic well-being would feel it as a "loss" with regard to their reference point. Using SHARE micro-economic individual panel data in Europe between 2006 and 2011, we find that on average, individuals compensate their "loss" by remaining active longer in the labour market - where earnings and economic opportunities are higher. This effect was larger than the opposite effect of leaving the workforce in the case of a "good surprise" 
suggesting that individuals attach more weight to losses than gains. We interpret this result as evidence of loss aversion when the reference point is based on expectations. We also find that loss aversion is more common among men, risk-averse individuals and those with a higher perceived life expectancy.

Our results can partly explain the modest reduction of labour force participation in the context of the 2009 crisis that the usual life-cycle determinants of retirement decisions could not realistically explain. However, the contribution to our understanding of the complex phenomena of retirement is small from a behavioural economics perspective. The relatively small proportion of individuals who report suffering a loss with regard to the reference point ("bad surprise") probably does not plead in favour of public or private strategies to help people make more accurate predictions. The paradox being that from a public policy perspective, the current trend in Europe is to encourage older people to work longer. 


\section{Acknowledgements}

This research was supported by a research grant from the Pension Division, Caisse des Dépôts et Consignation, Paris, France. The authors would like to thank Vincent Delsart, Isabelle Bridenne, Laurent Soulat, Tim Pullman, the participants to the $1^{\text {st }}$ International Conference on Globalization, Working Conditions and Health, Bordeaux, 25-27 june 2015, Stephen Bazen, and the anonymous referees for usefull comments. All errors remain ours. We declare no conflict of interest.

"This paper uses data from SHARE Wave 5 release 1.0.0, as of March 31st 2015 (DOI: 10.6103/SHARE.w5.100) or SHARE Wave 4 release 1.1.1, as of March 28th 2013 (DOI: 10.6103/SHARE.w4.111) or SHARE Waves 1 and 2 release 2.6.0, as of November 29th 2013 (DOI: 10.6103/SHARE.w1.260 and 10.6103/SHARE.w2.260) or SHARELIFE release 1.0.0, as of November 24th 2010 (DOI: 10.6103/SHARE.w3.100). The SHARE data collection has been primarily funded by the European Commission through the 5th Framework Programme (project QLK6-CT-2001-00360 in the thematic programme Quality of Life), through the 6th Framework Programme (projects SHARE-I3, RII-CT-2006-062193, COMPARE, CIT5- CT-2005-028857, and SHARELIFE, CIT4-CT-2006-028812) and through the 7th Framework Programme (SHARE-PREP, N 211909, SHARE-LEAP, Nº 227822 and SHARE M4, N 261982). Additional funding from the U.S. National Institute on Aging (U01 AG09740-13S2, P01 AG005842, P01 AG08291, P30 AG12815, R21 AG025169, Y1-AG-4553-01, IAG BSR06-11 and OGHA 04-064) and the German Ministry of Education and Research as well as from various national sources is gratefully acknowledged (see www.share-project.org for a full list of funding institutions).” 


\section{References}

Alavinia SM, Burdorf A (2008) "Unemployment and retirement and ill-health: a cross sectional analysis across European Countries”. Int Arch Occup Environ Health 82(1):39-45.

Altman, M. (2012). Implications of behavioural economics for financial literacy and public policy. The Journal of Socio-Economics, 41(5), 677-690.

Angelini, V., Cavapozzi, D. and Paccagnella, O. (2011). "Dynamics of reporting work disability in Europe". Journal of the Royal Statistical Society: Series A (Statistics in Society), 174: 621-638.

Aranki T. \& Macchiarelli C., (2013). "Employment Duration and Shifts into Retirement in the EU" LEQS - LSE 'Europe in Question' Discussion Paper Series 58, European Institute, LSE.

Arkes, H.R., Hirshleifer, D, Jiang, D., and Lim, S. (2008). "Reference Point Adaptation: Tests in the Domain of Security Trading”. Organizational Behavior and Human Decision Processes, 105, 67-81.

Barnay T. (2015) "Health, Work and Working Conditions: A Review of the European Economic Literature", European Journal of Health Economics, Online First, DOI: 10.1007/s10198-015-0715-8.

Behaghel L. and Blau D.M., (2012), "Framing Social Security Reform: Behavioral Responses to Changes in the Full Retirement Age", American Economic Journal: Economic Policy, American Economic Association, 4(4): 41-67.

Bonsang E. and van Soest A. (2012). "Satisfaction with Job and Income Among Older Individuals Across European Countries”. Social Indicators Research, 105(2): 227-254.

Bound, J. (1991), Self-Reported Versus Objective Measures of Health in Retirement Models, Journal of Human Resources, 26(1): 106-138.

Bütler, M., O. Huguenin and F. Teppa (2005): "What Triggers Early Retirement? Results from Swiss Pension Funds", C.E.P.R. Discussion Paper No.4394.

Camerer C., Babcock L. Loewenstein G. and Thaler R. (1997). "Labor Supply of New York City Cabdrivers: One Day at a Time.” Quarterly Journal of Economics, 112(2):407-441

Choi, M., Lohman, M. C., \& Mezuk, B. (2014). “Trajectories of cognitive decline by driving mobility: evidence from the Health and Retirement Study". International journal of geriatric psychiatry, 29(5), 447-453.

Coile, C. C., \& Levine, P. B. (2011). "Recessions, retirement, and social security". The American Economic Review, 101(3), 23-28.

Coppola M. and Wilke C.B. (2014), “At What Age Do You Expect to Retire? Retirement Expectations and Increases in the Statutory Retirement Age”, Fiscal Studies Volume 35, Issue 2, pages 165-188.

Crawford R. (2013), "The effect of the financial crisis on the retirement plans of older workers in England », Economics Letters 121, pp. 156-159

Cros J.G. (2008). “A Theory of Adaptive Economic Behavior”. Cambridge University Press.

Datta Gupta \& Kristensen N., (2008), "Work environment satisfaction and employee health: panel evidence from Denmark, France and Spain, 1994-2001", The European Journal of Health Economics, Springer, vol. 9(1), pp. 51-61

Dietrich, F., \& List, C. (2013). Where do preferences come from?. International Journal of Game Theory, 42(3), 613-637. 
Dorn D, Sousa-Poza A (2005), “The determinants of early retirement in Switzerland". Swiss J Econ Stat 141(2):247-283

Drobnič, S., Beham, B. and Präg, P. "Good job, good life? Working conditions and quality of life in Europe”, Social Indicators Research, Vol. 99, No. 2, 2010, pp. 205-225 (2010)

Dwyer DS, Mitchell OS (1999) "Health problems as determinants of retirement: Are self-rated measures endogenous?" Journal of Health Economics 18(2):173-193

Ferrie JE., Shipley MJ., Newman K., Stanfeld SA. and Marmot TM. (2005), 'Self-Reported Job Insecurity

Fisman, R., Jakiela, P., \& Kariv, S. (2015). How did distributional preferences change during the Great Recession?. Journal of Public Economics, 128, 84-95.

Garcia-Gomez P., "Institutions, Health Shocks and Labour Outcomes Across Europe,” Journal of Health Economics, 30(1), pp. 200-213. (2011)

García-Pérez J.I, Jiménez-Martín S., R. Sánchez-Martín A， (2013) "Retirement incentives, individual heterogeneity and labor transitions of employed and unemployed workers", Labour Economics, Volume 20, pp 106-120.

Gerardi, K., Goette, L., \& Meier, S. (2013). Numerical ability predicts mortgage default. Proceedings of the National Academy of Sciences, 110(28), 11267-11271.

Goda, G. S., Shoven, J. B., \& Slavo, S. N. (2011). "What Explains Changes in Retirement Plans during the Great Recession?". The American Economic Review, 101(3), 29-34.

Gustman, A. L., Steinmeier, T. L., \& Tabatabai, N. (2010). "What the Stock Market Decline Means for the Financial Security and Retirement Choices of the Near-Retirement Population”. The Journal of Economic Perspectives, 161-182.

Gustman, Alan L. \& Steinmeier, Thomas L., 2005. "The social security early entitlement age in a structural model of retirement and wealth," Journal of Public Economics, Elsevier, vol. 89(2-3), pages 441-463, February.

Hamermesh D. (1985), "Expectations, Life Expectancy, and Economic Behavior”, Quarterly Journal of Economics, 100(2): 389-408

Hurd M. \& McGarry K. (1995), "Evaluation of the Subjective Probabilities of Survival in the HRS”, Journal of Human Resources, Special Issue: The Health and Retirement Study, Data Quality and Early Results, 30(5): S268-S292.

Hurd M., McFadden D. \& Merrill A. (1999), "Predictors of Mortality Among the Elderly", NBER Working Papers, $\mathrm{n}^{\circ} 7440$.

Hurd M., Smith J. \& Zissimopoulos J. (2004), “The Effects of Subjective Survival on Retirement and Social Security Claiming", Journal of Applied Econometrics, 19(6): 761-775

Jones AM, Rice N, Roberts J (2010), "Sick of work or too sick to work? Evidence on self-reported health shocks and early retirement from the BHPS". Econ Modelling 27(4):866-880.

Kahneman, D., \& Tversky, A. (1979). "Prospect theory: An analysis of decision under risk". Econometrica: Journal of the Econometric Society, 263-291.

Karasek R. \& Theorell T. (1990), "Healthy Work: Stress, Productivity, and the Reconstruction of Working Life", Basic Books, New York.

Knoll, M. A. (2011). "Behavioral and psychological aspects of the retirement decision”. Soc. Sec. Bull., 71, 15. 
Kőszegi, B., \& Rabin, M. (2006). “A model of reference-dependent preferences”. The Quarterly Journal of Economics, 1133-1165.

Li, X., Hurd, M., \& Loughran, D. S. (2008). "The characteristics of social security beneficiaries who claim benefits at the early entitlement age" (Vol. 19). AARP, Public Policy Institute.

Lindeboom M. (2006) "Health and Work of Older Workers", in: A.M. Jones (ed.), Elgar Companion to Health Economics. Edward Elgar, Cheltenham.

Llena-Nozal A. (2009), "The effect of work status and working conditions on mental health in four OECD countries", National Institute Economic Review, 209(1), pp. 72-87

Masiero L. and Hensher, D. (2011). "Shift of reference point and implications on behavioral reaction to gains and losses". Transportation. 38(2): 249-271.

Pesendorfer, W. (2006). "Behavioral economics comes of age: a review essay on Advances in Behavioral Economics". Journal of Economic Literature, 44(3), 712-721.

Riedel M, Helmut Hofer H. and Wögerbauer B. (2015), IZA Journal of European Labor Studies (2015) 4:4 DOI 10.1186/s40174-014-0027-5

Schwartz, A., Goldberg, J., Hazen, G. (2008) "Prospect theory, reference points, and health decisions". Judgement and Decision Making, 3(2): 174-180.

Siegrist J. (1996), “Adverse Health Effects of High-Effort/Low-Reward Conditions”, Journal of Occupational Health Psychology, 1(1): 27-41Strauss and Thomas, 1998

Strauss, J., \& Thomas, D. (1998). "Health, nutrition, and economic development". Journal of economic literature, 36(2), 766-817.

Szinovacz, M. E., Martin, L., \& Davey, A. (2014). "Recession and expected retirement age: Another look at the evidence". The Gerontologist, 54(2), 245-257.

Tversky, A. \& Kahneman, D. (1991). "Loss Aversion in Riskless Choice: A Reference Dependent Model". Quarterly Journal of Economics 106, 1039-1061.

Väänänen A., Pahkin K, Kalimo R \& Buuk B.P. (2004), "Maintenance of subjective health during a merger: the role of experienced change and pre-merger social support at work in white- and blue-collar workers" Social Science and Medicine, 58(10): 1903-1915.

van Solinge H, Henkens K (2009) "Living longer, working longer? The impact of subjective life expectancy on retirement intentions and behavior”. Eur J Public Health 20(1):47-51

Wilson, T. D., \& Gilbert, D. T. (2003). “Affective forecasting”. Advances in experimental social psychology, 35, 345-411. 


\section{Figure 1}

Job Retention Rate in 2011 among 50-65 years-old at Work in 2006.

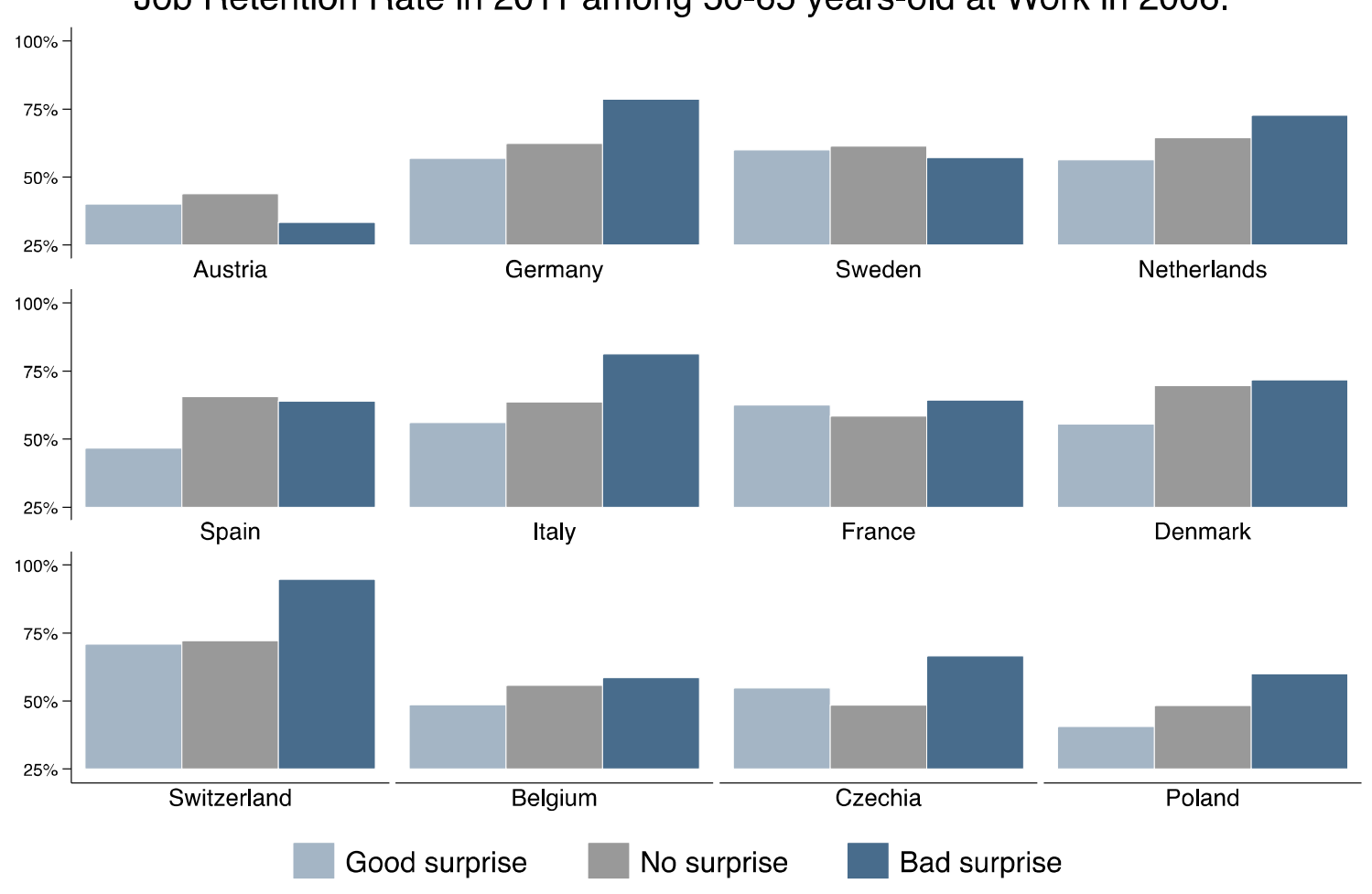

Source: SHARE waves 2 and 4. 


\section{Tables}

Table 1: Sample Characteristics

\begin{tabular}{|c|c|c|c|c|c|}
\hline Variables & Obs & Mean & Std. Dev. & Min & Max \\
\hline \multicolumn{6}{|l|}{ Changes between waves 2 and 4} \\
\hline \multicolumn{6}{|l|}{ Labour market } \\
\hline Still at work (Dep. Var.) & 4054 & 0.623 & 0.485 & 0 & 1 \\
\hline \multicolumn{6}{|l|}{ Living standards } \\
\hline Bad surprise & 4054 & 0.038 & 0.192 & 0 & 1 \\
\hline No surprise (ref.) & 4054 & 0.894 & 0.307 & 0 & 1 \\
\hline Good surprise & 4054 & 0.067 & 0.251 & 0 & 1 \\
\hline Prob. Gain (+) or Loss(-) in the future (Expected) & 4054 & -0.044 & 0.678 & -1 & 1 \\
\hline Experienced Gain(+) or Loss(-) at wave 4 & 4054 & 0.090 & 0.823 & -3 & 3 \\
\hline \multicolumn{6}{|l|}{ Health and social } \\
\hline Onset of chronic disease & 4054 & 0.233 & 0.423 & 0 & 1 \\
\hline Marital status changed & 4054 & 0.059 & 0.236 & 0 & 1 \\
\hline \multicolumn{6}{|l|}{ Socio-demog. characteristics (at baseline) } \\
\hline Age & 4054 & 56 & 3.7 & 50 & 65.9 \\
\hline Gender (Female) & 4054 & 0.486 & 0.5 & 0 & 1 \\
\hline \multicolumn{6}{|l|}{ Education } \\
\hline Lower than High School & 4054 & 0.263 & 0.441 & 0 & 1 \\
\hline High School or College & 4054 & 0.363 & 0.481 & 0 & 1 \\
\hline University & 4054 & 0.373 & 0.484 & 0 & 1 \\
\hline Migrant (Not born in the country of residence) & 4054 & 0.061 & 0.240 & 0 & 1 \\
\hline Caregiver (to give help outside the hhd) & 4054 & 0.408 & 0.491 & 0 & 1 \\
\hline \multicolumn{6}{|l|}{ Spouse's work status } \\
\hline No spouse & 4054 & 0.171 & 0.377 & 0 & 1 \\
\hline Spouse works & 4054 & 0.430 & 0.495 & 0 & 1 \\
\hline Spouse does not work & 4054 & 0.237 & 0.425 & 0 & 1 \\
\hline Status unknown & 4054 & 0.163 & 0.369 & 0 & 1 \\
\hline Child burden (18-24 \& educ, unemployed, or at home) & 4054 & 0.317 & 0.465 & 0 & 1 \\
\hline \multicolumn{6}{|l|}{ Health, Work and Wealth (at baseline) } \\
\hline Poor Self-Rated Health & 4054 & 0.153 & 0.189 & 0.019 & 0.995 \\
\hline Cognitive performance & 4054 & 0.452 & 0.111 & 0 & 0.883 \\
\hline \multicolumn{6}{|l|}{ Type of employment } \\
\hline Employee & 4054 & 0.712 & 0.453 & 0 & 1 \\
\hline Civil servant & 4054 & 0.134 & 0.341 & 0 & 1 \\
\hline Self-employed & 4054 & 0.154 & 0.361 & 0 & 1 \\
\hline Satisfied with job & 4054 & 0.458 & 0.498 & 0 & 1 \\
\hline Household Net Assets / 1m€ (PPP) & 4054 & 0.810 & 1.817 & -30.7 & 38.8 \\
\hline \multicolumn{6}{|l|}{ Life-course events (wave 3: SHARELIFE) } \\
\hline Financial difficulties in adult life & 4054 & 0.353 & 0.478 & 0 & 1 \\
\hline Health issues in adult life & 4054 & 0.198 & 0.399 & 0 & 1 \\
\hline \multicolumn{6}{|l|}{ Behavioural measures (at baseline) } \\
\hline Expects long life & 3902 & 0.687 & 0.464 & 0 & 1 \\
\hline Risk-averse & 2837 & 0.586 & 0.493 & 0 & 1 \\
\hline
\end{tabular}


Table 2: Change in living standards between waves 2 and 4

\begin{tabular}{lcccc}
\hline & \multicolumn{3}{c}{ Expected } & \multirow{2}{*}{ Total } \\
\cline { 2 - 4 } & Worsen & Stable & Improve & \\
\hline Experienced & & & & \\
Worsen & 4.86 & 10.61 & 3.82 & 19.29 \\
Stable & 13.67 & 28.64 & 11.05 & 53.35 \\
Improve & 6.73 & 14.60 & 6.02 & 27.36 \\
& & & & \\
\hline Total & 25.26 & 53.85 & 20.89 & 100 \\
\hline \hline
\end{tabular}

Table 3: Sample Main Caracteristics by Country And Euro-region

\begin{tabular}{|c|c|c|c|c|c|}
\hline \multirow{2}{*}{ Country } & \multirow{2}{*}{ N. Indiv. } & \multicolumn{4}{|c|}{ Proportion of indiv. still at work at wave 4} \\
\hline & & All & Good surprise(a) & No surprise & Bad surprise(a) \\
\hline North & 1401 & 0.666 & $0.538 * *$ & 0.669 & 0.733 \\
\hline Denmark & 621 & 0.705 & $0.444^{*}$ & 0.706 & 0.792 \\
\hline Netherlands & 402 & 0.652 & 0.560 & 0.652 & 0.833 \\
\hline Sweden & 378 & 0.616 & 0.556 & 0.624 & 0.444 \\
\hline Continental & 1653 & 0.618 & 0.620 & 0.613 & $0.761 * *$ \\
\hline Austria & 71 & 0.423 & 0.286 & 0.435 & 0.500 \\
\hline Belgium & 448 & 0.549 & 0.444 & 0.547 & 0.684 \\
\hline France & 410 & 0.605 & 0.689 & 0.588 & 0.714 \\
\hline Germany & 351 & 0.630 & 0.579 & 0.630 & 0.800 \\
\hline Switzerland & 373 & 0.740 & 0.846 & 0.730 & $1.000 *$ \\
\hline Eastern & 524 & 0.492 & 0.460 & 0.486 & $0.737 * *$ \\
\hline Czechia & 297 & 0.498 & 0.511 & 0.490 & 0.800 \\
\hline Poland & 227 & 0.485 & 0.333 & 0.482 & $0.714 *$ \\
\hline Southern & 296 & 0.662 & 0.524 & 0.656 & 0.778 \\
\hline Italy & 296 & 0.659 & 0.615 & 0.646 & 0.793 \\
\hline Spain & 180 & 0.667 & $0.375^{*}$ & 0.673 & 0.750 \\
\hline Total & 4054 & 0.623 & $0.560 * *$ & 0.622 & $0.755^{* * *}$ \\
\hline
\end{tabular}

Note: (a) Two-sample equality-of-propotion test, refernce is "No surprise". Legend: * $\mathrm{p}<0.1, * * \mathrm{p}<0.05, * * * \mathrm{p}<0.01$. 
Table 4: Probit Estimates of the determinants of staying at work - Stepwise

Dep. Var is "Still at work at wave 4"

(1)

(2)

(3)

(4)

\author{
Changes between waves 2 and 4 \\ Living standards \\ Bad surprise \\ Good surprise \\ No surprise (ref.) \\ Expected Gain at wave 2 \\ Experienced Gain at wave 4 \\ Health and social \\ Onset of chronic disease \\ Marital status changed
}

Socio-demog. characteristics (at baseline)

Age

Gender (Female)

Education

Lower than High School

High School or College

University

Migrant (Not born in the country of residence)

Caregiver (to give help outside the hhd)

Spouse's work status

No spouse

Spouse works

Spouse does not work

Status unknown

Child burden (18-24 \& educ, unemployed,or at home)

Health, Work and Wealth (at baseline)

Poor Self-Rated Health

Cognitive performance

Type of employment

Employee

Civil servant

Self-employed

Satisfied with job

Household Net Assets / 1m€ (PPP)

\begin{tabular}{|c|c|c|c|}
\hline & & $\begin{array}{c}0.099 * * \\
(0.049) \\
-0.022 \\
(0.040) \\
\text { Ref. }\end{array}$ & $\begin{array}{c}0.081 \\
(0.058) \\
-0.013 \\
(0.047) \\
\text { Ref. }\end{array}$ \\
\hline & & $\begin{array}{c}0.028 * \\
(0.016) \\
0.064 * * * \\
(0.012)\end{array}$ & $\begin{array}{c}0.032 * \\
(0.018) \\
0.063 * * * \\
(0.014)\end{array}$ \\
\hline & & $\begin{array}{c}-0.041 * * \\
(0.020) \\
0.069 * * \\
(0.033)\end{array}$ & $\begin{array}{c}-0.042 * \\
(0.024) \\
0.079 * * \\
(0.037)\end{array}$ \\
\hline $\begin{array}{c}-0.080 * * * \\
(0.003) \\
-0.050 * * * \\
(0.018)\end{array}$ & $\begin{array}{c}-0.080 * * * \\
(0.003) \\
-0.054 * * * \\
(0.018)\end{array}$ & $\begin{array}{c}-0.079 * * * \\
(0.003) \\
-0.053 * * * \\
(0.018)\end{array}$ & $\begin{array}{c}-0.074 * * * \\
(0.003) \\
-0.031 \\
(0.021)\end{array}$ \\
\hline $\begin{array}{c}\text { Ref. } \\
-0.002 \\
(0.023)\end{array}$ & $\begin{array}{c}\text { Ref. } \\
-0.002 \\
(0.023)\end{array}$ & $\begin{array}{c}\text { Ref. } \\
-0.004 \\
(0.023)\end{array}$ & $\begin{array}{c}\text { Ref. } \\
-0.010 \\
(0.028)\end{array}$ \\
\hline $\begin{array}{c}0.085 * * * \\
(0.023)\end{array}$ & $\begin{array}{c}0.086 * * * \\
(0.023)\end{array}$ & $\begin{array}{c}0.083 * * * \\
(0.023)\end{array}$ & $\begin{array}{c}0.104 * * * \\
(0.027)\end{array}$ \\
\hline $\begin{array}{c}0.127 * * * \\
(0.031)\end{array}$ & $\begin{array}{c}0.125 * * * \\
(0.031)\end{array}$ & $\begin{array}{c}0.127 * * * \\
(0.031)\end{array}$ & $\begin{array}{c}0.119 * * * \\
(0.036)\end{array}$ \\
\hline $\begin{array}{c}0.000 \\
(0.017)\end{array}$ & $\begin{array}{c}0.001 \\
(0.017)\end{array}$ & $\begin{array}{l}-0.003 \\
(0.017)\end{array}$ & $\begin{array}{l}-0.013 \\
(0.021)\end{array}$ \\
\hline $\begin{array}{c}\text { Ref. } \\
-0.027 \\
(0.025) \\
-0.096 * * * \\
(0.028) \\
0.000 \\
(0.030)\end{array}$ & $\begin{array}{c}\text { Ref. } \\
-0.021 \\
(0.025) \\
-0.091 * * * \\
(0.028) \\
0.003 \\
(0.030)\end{array}$ & $\begin{array}{c}\text { Ref. } \\
-0.025 \\
(0.025) \\
-0.093 * * * \\
(0.028) \\
-0.001 \\
(0.031)\end{array}$ & $\begin{array}{c}\text { Ref. } \\
-0.032 \\
(0.028) \\
-0.067 * * \\
(0.033) \\
-0.006 \\
(0.030)\end{array}$ \\
\hline $\begin{array}{c}0.044 * * \\
(0.019)\end{array}$ & $\begin{array}{c}0.041 * * \\
(0.019)\end{array}$ & $\begin{array}{l}0.037 * \\
(0.019)\end{array}$ & $\begin{array}{l}0.039 * \\
(0.022)\end{array}$ \\
\hline $\begin{array}{c}-0.178 * * * \\
(0.046) \\
0.156 * \\
(0.084)\end{array}$ & $\begin{array}{c}-0.132 * * * \\
(0.047) \\
0.152 * \\
(0.084)\end{array}$ & $\begin{array}{c}-0.122 * * \\
(0.048) \\
0.171 * * \\
(0.084)\end{array}$ & $\begin{array}{c}-0.141 * * \\
(0.057) \\
0.111 \\
(0.101)\end{array}$ \\
\hline $\begin{array}{c}\text { Ref. } \\
-0.012 \\
(0.026)\end{array}$ & $\begin{array}{c}\text { Ref. } \\
-0.012 \\
(0.026)\end{array}$ & $\begin{array}{c}\text { Ref. } \\
-0.012 \\
(0.026)\end{array}$ & $\begin{array}{c}\text { Ref. } \\
-0.004 \\
(0.031)\end{array}$ \\
\hline $\begin{array}{c}0.175 * * * \\
(0.021)\end{array}$ & $\begin{array}{c}0.174 * * * \\
(0.021)\end{array}$ & $\begin{array}{c}0.173 * * * \\
(0.021)\end{array}$ & $\begin{array}{c}0.157 * * * \\
(0.024)\end{array}$ \\
\hline $\begin{array}{c}0.049 * * * \\
(0.017)\end{array}$ & $\begin{array}{c}0.051 * * * \\
(0.017)\end{array}$ & $\begin{array}{c}0.049 * * * \\
(0.018)\end{array}$ & $\begin{array}{c}0.077 * * * \\
(0.021)\end{array}$ \\
\hline $0.013 * * *$ & $0.014 * * *$ & $0.014 * * *$ & $0.013 * *$ \\
\hline
\end{tabular}

Continued on next page 
Table 4 continued...

Life-course events (wave 3: SHARELIFE)

Financial difficulties in adult life

Health issues in adult life

Life-course events (wave 3: SHARELIFE)

Financial difficulties in adult life

Health issues in adult life

$\begin{array}{cccc}(0.004) & (0.005) & (0.005) & (0.005) \\ & 0.035^{* *} & 0.031^{*} & 0.021 \\ & (0.018) & (0.018) & (0.021) \\ -0.096^{* * *} & -0.096^{* * *} & -0.092 * * * \\ (0.023) & (0.023) & (0.028)\end{array}$

\begin{tabular}{lcccc} 
& & & \multicolumn{2}{c}{$(0.021)$} \\
Country dummies & & & & Yes \\
\hline N. Obs. & Yes & Yes & Yes & 2746 \\
Pseudo R2 (McFadden) & 4054 & 4054 & 4054 & 0.261 \\
Correctly classified & 0.257 & 0.261 & 0.270 & 0.773 \\
LR test (Chi2) & 0.773 & 0.771 & 0.779 & 0.130 \\
LR test (p-value) & 1379.43 & 22.26 & 50.18 & 0.937 \\
\hline \hline
\end{tabular}

Note: Marginal effects; Robust standard errors in parentheses. LR test: (a) Model 1 vs. constant only model; (b) Model 4 vs. 3 with the same N. Obs. Legend: $* \mathrm{p}<0.1, * * \mathrm{p}<0.05, * * * \mathrm{p}<0.01$ 
Table 5: Probit Estimates of the determinants of staying at work - Decomposition by gender and behavioural variables

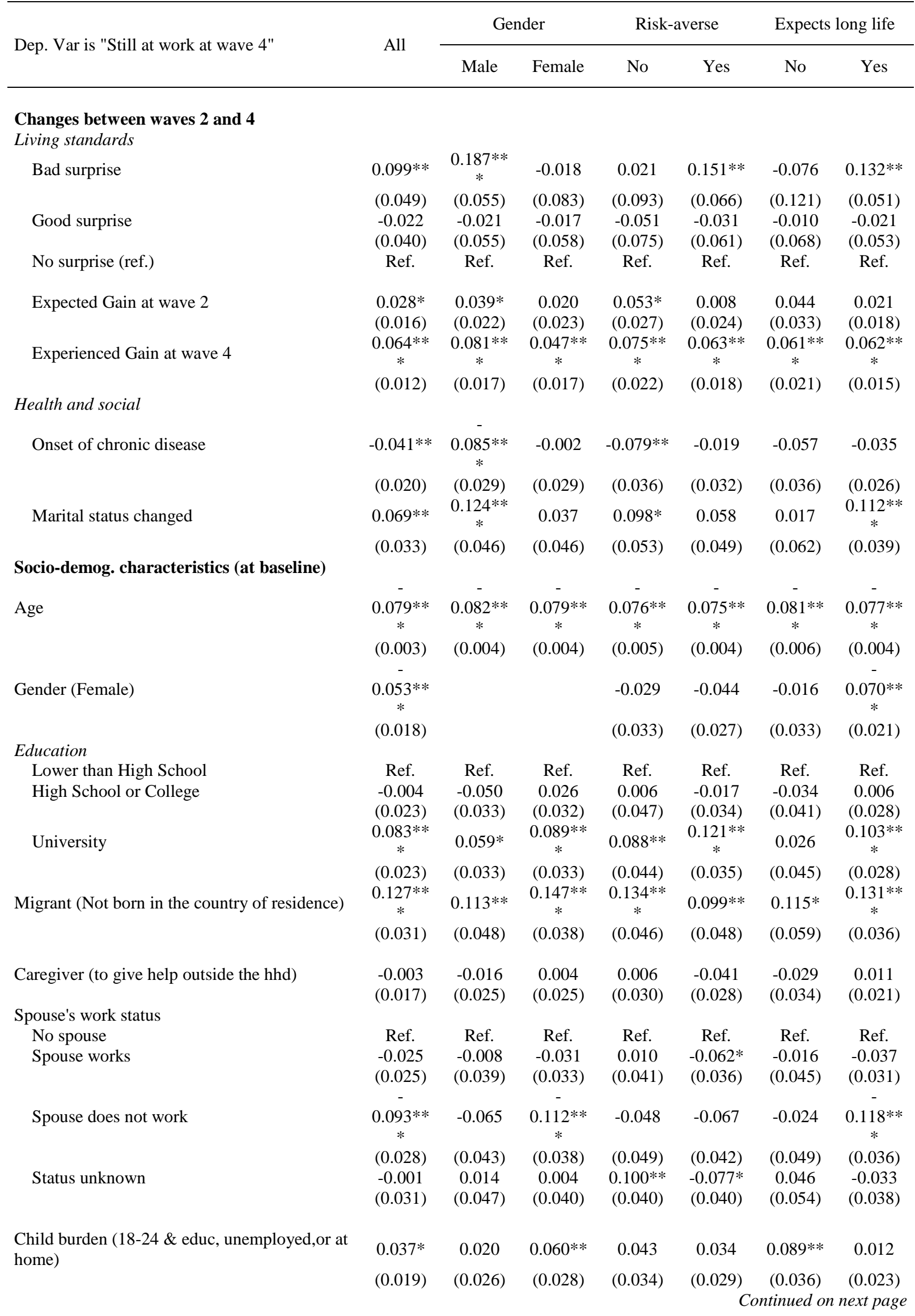


Table 5 continued...

Health, Work and Wealth (at baseline)

\begin{tabular}{|c|c|c|c|c|c|c|c|}
\hline \multirow[t]{2}{*}{ Poor Self-Rated Health } & $0.122 * *$ & -0.122 & $0.134 * *$ & $-0.151 *$ & -0.113 & -0.101 & $\begin{array}{c}0.174 * * \\
*\end{array}$ \\
\hline & $(0.048)$ & $(0.076)$ & $(0.062)$ & $(0.084)$ & $(0.073)$ & $(0.075)$ & $(0.067)$ \\
\hline \multirow[t]{2}{*}{ Cognitive performance } & $0.171 * *$ & $0.226^{*}$ & 0.140 & -0.223 & $0.324 * *$ & $\begin{array}{c}0.416^{* *} \\
*\end{array}$ & 0.087 \\
\hline & $(0.084)$ & $(0.121)$ & $(0.119)$ & $(0.153)$ & $(0.131)$ & $(0.149)$ & $(0.106)$ \\
\hline \multicolumn{8}{|l|}{ Type of employment } \\
\hline Employee & Ref. & Ref. & Ref. & Ref. & Ref. & Ref. & Ref. \\
\hline Civil servant & -0.012 & -0.029 & 0.004 & 0.068 & -0.046 & -0.020 & -0.013 \\
\hline \multirow[t]{2}{*}{ Self-employed } & $\begin{array}{c}(0.026) \\
0.173 * * \\
*\end{array}$ & $\begin{array}{c}(0.038) \\
0.221 * * \\
*\end{array}$ & $\begin{array}{c}(0.038) \\
0.111 * * \\
*\end{array}$ & $\begin{array}{c}(0.043) \\
0.123 * * \\
*\end{array}$ & $\begin{array}{c}(0.042) \\
0.192 * * \\
*\end{array}$ & $\begin{array}{c}(0.054) \\
0.166^{* *} * \\
*\end{array}$ & $\begin{array}{c}(0.031) \\
0.183 * * \\
*\end{array}$ \\
\hline & $(0.021)$ & $(0.026)$ & $(0.035)$ & $(0.036)$ & $(0.031)$ & $(0.043)$ & $(0.024)$ \\
\hline \multirow[t]{2}{*}{ Satisfied with job } & $\begin{array}{c}0.049 * * \\
*\end{array}$ & $\begin{array}{c}0.095 * * \\
*\end{array}$ & 0.006 & $\begin{array}{c}0.103 * * \\
*\end{array}$ & $0.059 * *$ & $0.074 * *$ & $0.040^{*}$ \\
\hline & $(0.018)$ & $(0.025)$ & $(0.025)$ & $(0.031)$ & $(0.027)$ & $(0.034)$ & $(0.021)$ \\
\hline \multirow[t]{2}{*}{ Household Net Assets / 1m€ (PPP) } & $\begin{array}{c}0.014 * * \\
*\end{array}$ & $\begin{array}{c}0.017 * * \\
*\end{array}$ & 0.006 & $\begin{array}{c}0.016 * * \\
*\end{array}$ & 0.016 & 0.016 & $0.013 * *$ \\
\hline & $(0.005)$ & $(0.005)$ & $(0.009)$ & $(0.006)$ & $(0.010)$ & $(0.011)$ & $(0.005)$ \\
\hline \multicolumn{8}{|l|}{ Life-course events (wave 3: SHARELIFE) } \\
\hline \multirow[t]{2}{*}{ Financial difficulties in adult life } & $\begin{array}{l}0.031 * \\
(0.018)\end{array}$ & $\begin{array}{c}0.017 \\
(0.026)\end{array}$ & $\begin{array}{c}0.032 \\
(0.026)\end{array}$ & $\begin{array}{c}0.028 \\
(0.032)\end{array}$ & $\begin{array}{c}0.011 \\
(0.028)\end{array}$ & $\begin{array}{c}0.052 \\
(0.034)\end{array}$ & $\begin{array}{c}0.022 \\
(0.022)\end{array}$ \\
\hline & - & - & - & & - & & - \\
\hline \multirow[t]{2}{*}{ Health issues in adult life } & $\begin{array}{c}0.096 * * \\
*\end{array}$ & $\begin{array}{c}0.083 * * \\
*\end{array}$ & $\begin{array}{c}0.111 * * \\
*\end{array}$ & $-0.066^{*}$ & $\begin{array}{c}0.117 * * \\
*\end{array}$ & $0.086^{* *}$ & $\begin{array}{c}0.098 * * \\
*\end{array}$ \\
\hline & $(0.023)$ & $(0.032)$ & $(0.033)$ & $(0.039)$ & $(0.037)$ & $(0.039)$ & $(0.029)$ \\
\hline \multicolumn{8}{|l|}{ Country dummies } \\
\hline N. Obs. & 4054 & 2085 & 1969 & 1174 & 1663 & 1220 & 2682 \\
\hline Pseudo R2 (McFadden) & 0.270 & 0.297 & 0.266 & 0.302 & 0.257 & 0.258 & 0.281 \\
\hline Correctly classified & 0.779 & 0.786 & 0.785 & 0.797 & 0.766 & 0.766 & 0.782 \\
\hline
\end{tabular}

Note: Marginal effects; Robust standard errors in parentheses.Legend: $* \mathrm{p}<0.1, * * \mathrm{p}<0.05, * * * \mathrm{p}<0.01$ 
16-3. How do product and labor market regulations affect aggregate employment, inequalities and job polarization? A general equilibrium approach

Julien Albertini, Jean-Olivier Hairault, François Langot, Thepthida Sopraseuth

16-2. Acces to employment with age and gender: results of a controlled experiment Laetitia Challe, Florent Fremigacci, François Langot, Yannick L'Horty, Loïc Du Parquet, Pascale Petit

16-1. An evaluation of the 1987 French Disabled Workers Act: Better paying than hiring

Thomas Barnay, Emmanuel Duguet, Christine Le Clainche, Yann Videau 
15-10. Optimal Income Taxation with Unemployment and Wage Responses: A Sufficient Statistics Approach

Kory Kroft, Kavan Kucko, Etienne Lehmann, Johannes Schmieder

15-9. Search frictions and (in) efficient vocational training over the life-cycle Arnaud Chéron, Anthony Terriau

15-8. Absenteeism and productivity: the experience rating applied to employer contributions to health insurance

Sébastien Ménard, Coralia Quintero Rojas

15-7. Take up of social assistance benefits: the case of homeless Sylvain Chareyron

15-6. Spatial mismatch through local public employment agencies. Answers from a French quasi-experiment

Mathieu Bunel, Elisabeth Tovar

15-5. Transmission of vocational skills at the end of career: horizon effect and technological or organisational change

Nathalie Greenan, Pierre-Jean Messe

15-4. Protecting biodiversity by developing bio-jobs: A multi-branch analysis with an application on French data

Jean De Beir, Céline Emond, Yannick L'Horty, Laetitia Tuffery

15-3. Profit-Sharing and Wages: An Empirical Analysis Using French Data Between 2000 and 2007

Noélie Delahaie, Richard Duhautois

15_2. A meta-regression analysis on intergenerational transmission of education: publication bias and genuine empirical effect

Nicolas Fleury, Fabrice Gilles

15_1. Why are there so many long-term unemployed in Paris?

Yannick L'Horty, Florent Sari 
14-14. Hiring discrimination based on national origin and the competition between employed and unemployed job seekers

Guillaume Pierné

14-13. Discrimination in Hiring: The curse of motorcycle women

Loïc Du Parquet, Emmanuel Duguet, Yannick L'Horty, Pascale Petit

14-12. Residential discrimination and the ethnic origin: An experimental assessment in the Paris suburbs

Emmanuel Duguet, Yannick L'Horty, Pascale Petit

14-11. Discrimination based on place of residence and access to employment Mathieu Bunel, Yannick L'Horty, Pascale Petit

14-10. Rural Electrification and Household Labor Supply: Evidence from Nigeria Claire Salmon, Jeremy Tanguy

14-9. Effects of immigration in frictional labor markets: theory and empirical evidence from EU countries

Eva Moreno-Galbis, Ahmed Tritah

14-8. Health, Work and Working Conditions: A Review of the European Economic Literature

Thomas Barnay

14-7. Labour mobility and the informal sector in Algeria: a cross-sectional comparison (2007-2012)

Philippe Adair, Youghourta Bellache

14-6. Does care to dependent elderly people living at home increase their mental health? Thomas Barnay, Sandrine Juin

14_5. The Effect of Non-Work Related Health Events on Career Outcomes: An Evaluation in the French Labor Market

Emmanuel Duguet, Christine le Clainche

14_4. Retirement intentions in the presence of technological change: Theory and evidence from France

Pierre-Jean Messe, Eva Moreno - Galbis, Francois-Charles Wolff

14_3. Why is Old Workers' Labor Market more Volatile? Unemployment Fluctuations over the Life-Cycle

Jean-Olivier Hairault, François Langot, Thepthida Sopraseuth

14_2. Participation, Recruitment Selection, and the Minimum Wage

Frédéric Gavrel

14_1. Disparities in taking sick leave between sectors of activity in France: a longitudinal analysis of administrative data

Thomas Barnay, Sandrine Juin, Renaud Legal 
13_9. An evaluation of the impact of industrial restructuring on individual human capital accumulation in France (1956-1993)

Nicolas Fleury, Fabrice Gilles

13_8. On the value of partial commitment for cooperative investment in buyer-supplier relationship

José de Sousa, Xavier Fairise

13-7. Search frictions, real wage rigidities and the optimal design of unemployment insurance

Julien Albertini, Xavier Fairise

13-6. Tax me if you can! Optimal non linear income tax between competing governments Etienne Lehmann, Laurent Simula, Alain Trannoy

13-5. Beyond the labour income tax wedge: The unemployment-reducing effect of tax progressivity

Etienne Lehmann, Claudio Lucifora, Simone Moriconi, Bruno Van Der Linden

13-4. Discrimination based on place of residence and access to employment

Mathieu Bunel, Emilia Ene Jones, Yannick L'Horty, Pascale Petit

12-3. The determinants of job access channels: evidence from the youth labor market in Franc

Jihan Ghrairi

13-2. Capital mobility, search unemployment and labor market policies: The case of minimum wages

Frédéric Gavrel

13-1. Effort and monetary incentives in Nonprofit et For-Profit Organizations Joseph Lanfranchi, Mathieu Narcy 
The CNRS Institute for Labor Studies and Public Policies (the TEPP Institute, FR n ${ }^{\circ} 3435$ CNRS) gathers together research centres specializing in economics and sociology:

- L'Equipe de Recherche sur l'Utilisation des Données Individuelles en lien avec la Théorie Economique (Research Team on Use of Individuals Data in connection with economic theory), ERUDITE, University of Paris-Est Créteil and University of ParisEst Marne-la-Vallée

- Le Centre d'Etudes des Politiques Economiques de l'université d'Evry (Research Centre focused on the analysis of economic policy and its foundations and implications), EPEE, University of Evry Val d'Essonne

- Le Centre Pierre Naville (Research on Work and Urban Policies), CPN, University of Evry Val d'Essonne

- Le Groupe d'Analyse des Itinéraires et des Niveaux Salariaux (Group on Analysis of Wage Levels and Trajectories), GAINS, University of the Maine

- Le Centre de Recherches en Economie et en Management, (Research centre in Economics and Management), CREM, University of Rennes 1 et University of Caen Basse-Normandie

- Le Groupe de Recherche ANgevin en Économie et Management (Angevin Research Group in Economics and Management), GRANEM, University of Angers ;

- Le Centre de Recherche en Economie et Droit (Research centre in Economics and Law) CRED, University of Paris II Panthéon-Assas ;

- Le Laboratoire d'Economie et de Management Nantes-Atlantique (Laboratory of Economics and Management of Nantes-Atlantique) LEMNA, University of Nantes ;

- Le Laboratoire interdisciplinaire d'étude du politique Hannah Arendt - Paris Est, LIPHA-PE

The TEPP Institute brings together 190 researchers and research professors and $140 \mathrm{PhD}$ students who study changes in work and employment in relation to the choices made by firms and analyse public policies using new evaluation methods. 